\title{
IDOSOS NA EDUCAÇÃO DE JOVENS E ADULTOS NO MUNICÍPIO DE JOÃO PESSOA: UMA REALIDADE VISÍVEL
}

\author{
ELDERLY PEOPLE IN THE YOUTH AND ADULT EDUCATION \\ IN THE CITY OF JOÃO PESSOA: A VISIBLE REALITY
}

\section{LOS ADULTOS MAYORES EN LA EDUCACIÓN DE JÓVENES $Y$ ADULTOS EN EL MUNICIPIO DE JOÃO PESSOA: UNA REALIDAD VISIBLE}

\author{
SAulo José Veloso de ANDRAdE ${ }^{\mathrm{I}}$ \\ THEÓFFILlo Silva LOPES ${ }^{1}$ \\ EDUARDO JORGE LOPES DA SILVA ${ }^{1}$ \\ ${ }^{\mathrm{I}}$ Universidade Federal da Paraíba (UFPB), João Pessoa/PB - Brasil
}

RESUmo Considerando as pesquisas demográficas realizadas no Brasil nos últimos anos, percebe-se o envelhecimento natural da população brasileira. Desse modo, em vários espaços sociais é possível vislumbrar uma forte presença de indivíduos que já ultrapassaram os 60 anos de idade e entraram na categoria dos idosos. À baila desse novo movimento, o presente artigo busca analisar os dados quantitativos que registram a presença de educandos idosos nas escolas municipais de João Pessoa-PB, demostrando, assim, que as unidades que atendem a EJA sinalizam para o estreitamento entre o atendimento de idosos no contexto educacional e o crescimento desse público no contexto da sociedade. Trata-se de um estudo qualitativo, teórico, que busca nos dados apresentados no Censo Escolar de 2014 a 2018 analisar a presença desse substrato social como sujeitos da EJA. Os dados revelados trazem à tona o debate sobre o direito à educação, previsto em diversos documentos oficiais, como o Estatuto do Idoso (2003), entre outros, além de ampliar o debate acerca do papel da escola e sua postura frente a essa demanda que vem se tornando crescente. Diante da presença dos idosos na escola, torna-se necessário preparar essas unidades para um novo desafio social, o envelhecimento da sociedade. Por fim, o estudo possibilitou compreender que os dados numéricos apontam para a presença dos idosos no contexto educacional, favorecendo inclusive a ampliação do debate sobre o modelo de escola que atende a esse outro perfil de educandos.

Palavras-chave: EJA; Escola; Idosos. 
ABSTRACT Considering the demographic surveys carried out in Brazil in recent years, the natural aging of the Brazilian population is clear. Thus, in a number of social spaces it is possible to observe the strong presence of individuals in their 60 s or more, who have thereby entered the category of elderly. In the light of this increasing movement, this article aims to analyze the quantitative data that record the presence of elderly students in the municipal schools of João Pessoa (PB), thereby demonstrating that units serving Youth and Adult Education (referred to as EJA in Brazilian Portuguese) reflect the narrowing between the literacy of the elderly in the Brazilian educational system and the growth of the elderly population in Brazil. This is a qualitative, theoretical study, which seeks to analyze the presence of this social substrate as subjects of EJA in the data presented in the 2014 to 2018 School Census. The analysis of the figures brings about the debate on the right to education, foreseen in several official documents, such as the Statute of the Elderly (2003), among others, in addition to broadening the debate on the role of the school and its position in face of this demand that has been growing. Given the presence of the elderly in schools, it is essential to prepare these units for a new social challenge, the aging of society. Finally, the study makes it possible to understand that the quantitative data point to the presence of the elderly in the educational context, even favoring the expansion of the debate on the school model that meets such a profile of students.

Keywords: Youth and Adult Education; School; Seniors.

RESUMEN Teniendo en cuenta las investigaciones demográficas realizadas en Brasil en los últimos años, se percibe el envejecimiento natural de la población brasileña. Así, en diversos espacios sociales es posible vislumbrar una fuerte presencia de individuos que ya han superado los 60 años y han entrado en la categoría de ancianos. A la luz de este nuevo movimiento, este artículo pretende analizar los datos cuantitativos que registran la presencia de alumnos mayores en las escuelas municipales de João Pessoa-PB, demostrando así que las unidades que atienden a la EJA señalan el estrechamiento entre la atención a los mayores en el contexto educativo y el crecimiento de este público en el contexto de la sociedad. Se trata de un estudio cualitativo, teórico, que busca en los datos presentados en el Censo Escolar 2014 a 2018 analizar la presencia de este sustrato social como sujetos de la EJA. Los datos revelados traen a colación el debate sobre el derecho a la educación, previsto en diversos documentos oficiales, como el Estatuto del Mayor (2003), entre otros, además de ampliar el debate sobre el papel de la escuela y su actitud ante esta demanda que ha ido en aumento. Dada la presencia de personas mayores en la escuela, se hace necesario preparar a estas unidades para un nuevo reto social, el envejecimiento de la sociedad. Finalmente, el estudio permitió entender que los datos numéricos apuntan a la presencia de los mayores en el contexto educativo, favoreciendo incluso la ampliación del debate sobre el modelo de escuela que atiende a este otro perfil de alumnos.

Palabras clave: EJA; Escuela; Ancianos. 


\section{Palavras iniciais}

Pensar a educação é refletir sobre uma gama de artefatos que povoam e compõem o cenário escolar, sobretudo no que tange aos indivíduos. Desde as crianças da Educação Infantil, que chegam à escola para as suas primeiras experiências escolares, até os idosos que fazem parte da Educação de Jovens e Adultos (EJA) e de outras modalidades da educação, cada grupo traz consigo suas especificidades, tornando a escola um campo ainda mais complexo.

É pensando nos públicos específicos que estão alocados no campo escolar que construímos o presente estudo, cujas reflexões focalizarão na pessoa idosa e sua presença na educação. Pela idade, naturalmente, esse público está presente na Educação Superior, na Educação Profissional, ou de forma mais enfática, na EJA. O que caracteriza uma necessidade, para a educação, de esforços e estudos sobre a práxis educativa no intuito de entender e atender às especificidades desse público.

À vista disso, o presente estudo tem como objetivo principal analisar a presença dos idosos e suas interfaces no contexto da escola, tendo como pano de fundo a série histórica das matrículas entre os anos de 2014 e 2018 das escolas da rede pública municipal da cidade de João Pessoa-PB, reforçando a forte presença desses sujeitos nas salas de aula. Outro aspecto que ratifica nossa escolha é o próprio processo de envelhecimento da sociedade, que avançou de maneira considerável.

Diante desses importantes aspectos, pensar o local dos idosos na sociedade, principalmente no campo da educação, emerge como uma necessidade. São muitos os questionamentos que podemos tecer a respeito desse importante assunto. Por exemplo: Quais mudanças no campo dos pressupostos teórico-metodológicos foram feitas para atender aos idosos nas escolas? Considerando esse e outros questionamentos, percebe-se a necessidade de se ampliar o debate acerca da presença desse grupo etário no contexto escolar.

Ao longo do presente estudo destacaremos elementos que vão demonstrar que a presença dos idosos vai se consolidando, haja vista que estamos vivenciando um processo de envelhecimento da sociedade brasileira nas últimas décadas. No entanto, é preciso compreender que não houve uma preparação da sociedade para abarcar o crescimento desse grupo de maneira tão rápida como tem acontecido.

Para que possamos melhor compreender esse processo que, em linhas gerais, reflete sobre a nossa própria existência, buscamos dialogar acerca do processo de envelhecimento no contexto da sociedade.

No primeiro momento deste trabalho denominado "Envelhecimento e Sociedade: desafios contemporâneos", buscamos refletir sobre o processo de envelhecimento pelo qual a sociedade atravessa, visto que se trata de um movimento que tende a evoluir.

Em seguida, trazemos uma intensa reflexão acerca da escola voltada para esse grupo etário, a qual denominamos $A$ escola dos 'velhos': refletindo sobre a Educação de Jovens e Adultos. Nesse item, discutimos a presença dos idosos nessa modalidade de ensino.

Dando continuidade, apresentamos o item Idosos na EJA no município de João Pessoa- $P B$, cujas reflexões são permeadas pelo debate acerca dos índices de matrículas desse segmento etário. Ao longo da discussão analisamos os números de matrículas dos últimos cincos anos, ou seja, entre os anos de 2014 e 2018, tendo como base o ano de realização 
desta pesquisa, 2019. Os dados apresentados reforçam a presença de idosos nas salas de EJA do município de João Pessoa-PB.

Quanto ao levantamento, categorização e análise dos dados, esclarecemos que o levantamento foi realizado junto a Subgerência de Estatística da Secretaria Estadual de Educação e da Ciência e Tecnologia do Governo do Estado da Paraíba (SGEST/SEECT/PB). E quanto a categorização e a análise, foram realizadas com base na Análise de Conteúdo preconizada por Bardin (2011), a partir da unidade de registro temática.

Finalizando esse debate, vislumbramos as Palavras finais. Nesse item, apontamos alguns aspectos que nitidamente reforçam a presença crescente desse grupo etário, ou seja, os idosos no contexto da sala de aula, mais precisamente na Educação de Jovens e Adultos do município de João Pessoa-PB.

\section{ENVELHECIMENTO E SOCIEDADE: DESAFIOS CONTEMPORÂNEOS}

A partir do processo de envelhecimento da sociedade brasileira, observamos o surgimento de inúmeros problemas, haja vista que se trata de um grupo que necessita de muitas mudanças, sejam elas no campo social, econômico ou mesmo educacional para a obtenção de uma vida saudável. Sobre esse processo de envelhecimento da sociedade é importante pensar que:

Até 2025, segundo a OMS, o Brasil será o sexto país do mundo em número de idosos. Ainda é grande a desinformação sobre a saúde do idoso e as particularidades e desafios do envelhecimento populacional para a saúde pública em nosso contexto social. Entre 1980 e 2000 a população com 60 anos ou mais cresceu 7,3 milhões, totalizando mais de 14,5 milhões em 2000. O aumento da expectativa média de vida também aumentou acentuadamente no país. Este aumento do número de anos de vida, no entanto, precisa ser acompanhado pela melhoria ou manutenção da saúde e qualidade de vida (WORLD HEALTH ORGANIZATION, 2005, p. 03).

Diante do exposto, percebemos a urgência que temos em nos adequar às necessidades desse grupo etário. É importante pensar que tais mudanças perpassam inclusive os aspectos de ser e estar na sociedade, ou seja, no que concerne ao tratamento dispensado a essas pessoas no cotidiano. Não podemos perceber os idosos, que são sujeitos de direitos, apenas por meio de alguns direitos ou ações que lhes são peculiares, como um assento preferencial ou a gratuidade de um serviço. É preciso ampliar uma gama de artefatos que possibilitem a esse cidadão maior tranquilidade nessa fase da vida.

Na exposição da World Health Organization (2005), destaca-se a preocupação com a relação entre o envelhecimento populacional e a qualidade de vida. Essa relação depende de uma série de fatores, entre os quais podemos destacar a educação, que tem se mostrado relevante a todos, fazendo surgir um novo conceito de educação para a vida. Isso demonstra o papel fundamental da educação na vida dos sujeitos, proporcionando emancipação, inserção social, autoestima e qualidade de vida.

Antes de avançarmos as discussões sobre esse grupo etário, faz-se necessário compreender o conceito de idoso que iremos adotar ao longo desse estudo. O conceito aqui apre- 
sentado está assentado nos documentos da Organização Mundial de Saúde (OMS), bem como no Estatuto do Idoso (2003) e outros documentos. Logo, é preciso compreender que:

Na realidade, existem diferentes formas de se definir e conceituar a velhice. Uma
delas é a definição preconizada pela Organização Mundial da Saúde, que é ba-
seada na idade cronológica, na qual a definição de idoso inicia aos 65 anos nos
países desenvolvidos e aos 60 anos nos países em desenvolvimento. No Brasil,
de acordo com o Estatuto do Idoso (2003), as pessoas com idade igual ou supe-
rior a 60 anos são reconhecidas como idosas. Entretanto, alguns direitos como
a gratuidade no transporte coletivo público urbano e semiurbano só é concedida
aos maiores de 65 anos (SCHNEIDER; IRIGARAY, 2008, p.589, grifos nossos).

Um fato que nos chama atenção é a disparidade entre a idade em que se considera idoso e a idade de garantia de direitos a alguns benefícios. Pois, embora se acolha como idoso as pessoas com 60 anos ou mais, somente aos 65 anos são concedidas algumas gratuidades. Desse modo, percebemos as lacunas que a legislação brasileira ainda tem no contexto de possibilitar a esses indivíduos uma melhor qualidade de vida através dos seus direitos.

Alinhados à idade cronológica, existem outros aspectos que, juntos, reforçam o contexto etário do ser humano. Nesse sentido, Schneider e Irigaray (2008) assentam em seus estudos quatro marcadores para a pessoa idosa, que correspondem às idades cronológica, biológica, psicológica e social.

Para os autores, esses marcadores demonstram que o idoso não pode ser vislumbrado apenas pela idade cronológica, mas, sobretudo, por um conjunto de aspectos que, juntos, situam esse indivíduo em sua plenitude. Considerar esses aspectos é perceber, aceitar e reconhecer que as características que constroem o sujeito idoso não estão atreladas exclusivamente ao tempo, mas também às suas relações, cotidiano, ambiente, convívios, anseios e objetivos.

Ainda de acordo com Schneider e Irigaray (2008), a idade cronológica versa sobre a idade em anos. Já a biológica destaca o envelhecimento do corpo que nem sempre acompanha a idade cronológica. A idade psicológica aponta para o comportamento do ser humano, que pode torná-lo mais velho ou mesmo mais novo, sendo um marcador que vai além dos anos vividos. Por último, temos o marcador da idade social, pois se trata de um construto social que aponta para aspectos os quais a sociedade situa sua concepção de idoso. Trata-se de um movimento no qual a sociedade incita elementos que ela considera pertinentes ou não para um grupo social. Portanto, é comum ouvir as pessoas dizerem: essa roupa não é para a sua idade, entre outros aspectos.

Discutir o idoso é pensar no processo de envelhecimento que, grosso modo, reluz em uma gama de artefatos que envolvem esse grupo no contexto da sociedade em que vivem. Um dos aspectos mais preocupantes em face desse grupo etário é o preconceito, a invisibilidade, sobretudo, quando nos referimos ao mercado de trabalho. Isso acontece em virtude de:

O modelo capitalista fez com que a velhice passasse a ocupar um lugar marginalizado na existência humana, na medida em que a individualidade já teria os seus potenciais evolutivos e perderia então o seu valor social. Desse modo, não tendo mais a possibilidade de produção de riqueza, a velhice perderia o seu valor simbólico (MENDES et al, 2005, p.425). 
Nesse contexto, o valor atribuído ao indivíduo tem uma intrínseca relação com a idade, ou seja, enquanto o sujeito está ativo no mercado de trabalho, o mesmo é reconhecido pela sociedade. No entanto, um dos marcadores do grande preconceito que vislumbramos na sociedade atual quanto à pessoa idosa, surge da invisibilidade em que se colocam esses sujeitos. Não se apontam os aspectos positivos desse grupo, como a contribuição, o legado, entre outros. O idoso é visto como uma pessoa que já passou, ou seja, que não tem grandes contribuições a fazer nessa fase da vida. Assim,

As concepções de velhice nada mais são do que resultado de uma construção social e temporal feita no seio de uma sociedade com valores e princípios próprios, que são atravessados por questões multifacetadas, multidirecionadas e contraditórias. Na época contemporânea, florescer do século XXI, ao mesmo tempo em que a sociedade potencializa a longevidade, ela nega aos velhos o seu valor e sua importância social. Vive-se em uma sociedade de consumo na qual apenas o novo pode ser valorizado, caso contrário, não existe produção e acumulação de capital. Nesta dura realidade, o velho passa a ser ultrapassado, descartado, ou já está fora de moda (SCHNEIDER; IRIGARAY, 2008, p. 587).

Superar essas máculas que são agregadas ao idoso é um dos grandes desafios que temos hoje em dia. Entretanto, inúmeros são os lugares de fuga desse grupo etário. Um dos espaços de fuga dos homens e mulheres que avançam no contexto da velhice é a escola.

No entanto, é preciso entender que o chegar à escola em muitos dos casos se dá por meio da Educação de Jovens e Adultos (EJA). Pois, em sua maioria, esse grupo teve segregado o direito à escolarização na idade regular de acesso à escola.

Quando nos referimos a esse público, em muitos casos, eles ingressam na escola para o processo de alfabetização, aprendendo as primeiras letras. Muitos são os motivos e expectativas que levam essas pessoas idosas de volta à escola.

Tendo em vista esse importante movimento, é preciso avançar no que tange a melhor compreender essas escolas que abarcam homens e mulheres que chegam a uma idade apontada para o descanso e para uma vida mais tranquila.

Embora se tenha garantido o acesso desse público à educação por meios dos documentos legais, como é o caso do Estatuto do Idoso (2003), ainda existem grandes problemas no que tange à adequação do ensino para esse grupo etário. Um dos grandes avanços no contexto da escolarização de pessoas idosas foi a incorporação da concepção de aprendizagem ao longo da vida para atender a esse grupo etário, compromisso assumido através do Marco Ação de Belém, documento fruto da VI Conferência Internacional de Educação de Adultos (VI CONFINTEA), realizada na cidade de Belém, no Estado do Pará, no ano de 2009.

Partindo da premissa de que tal documento aponta para a educação permanente, garantindo o direito de aprender em qualquer idade, ou seja, trazendo à tona a possibilidade de aprendizagem aos idosos, buscaremos refletir acerca da Educação de Jovens e Adultos como espaço que aglutina esse contingente populacional. 


\title{
A ESCOLA DOS "VELHOS": REFLETINDO SOBRE A EDUCAÇÃO DE JOVENS E ADULTOS
}

A Constituição Federal de 1988 diz em seu Art. 205 que "a educação, direito de todos e dever do Estado e da família, será promovida e incentivada com a colaboração da sociedade, visando ao pleno desenvolvimento da pessoa, seu preparo para o exercício da cidadania e sua qualificação para o trabalho", ou seja, é um direito universal, que independe da idade ou de quaisquer outras questões. Partindo desse ideário contido na Constituição, buscamos refletir sobre a educação voltada para os idosos.

Não se trata de criar uma nova escola para um segmento específico, mas de oportunizar a esse grupo etário o acesso a uma instituição educacional que atenda às suas especificidades. Desse modo, o próprio Estatuto do Idoso já lhes garante esse processo quando em seu Art. 22 diz que: "Nos currículos mínimos dos diversos níveis de ensino formal serão inseridos conteúdos voltados ao processo de envelhecimento, ao respeito e à valorização do idoso, de forma a eliminar o preconceito e a produzir conhecimentos sobre a matéria".

Essa adequação curricular trata da, assim chamada, função equalizadora contida no parecer CNE/CEB n ${ }^{\circ} 11 / 2000$, que versa sobre as Diretrizes Curriculares Nacionais para Educação de Jovens e Adultos e que estabelece três principais funções para a modalidade: reparar, equalizar e qualificar.

A EJA é, a priori, o principal acesso das pessoas idosas à educação escolar, haja vista sua organização. Sabemos, entretanto, que existem inúmeros idosos em espaços escolares além da Educação Básica em que está abarcada a EJA. Essa modalidade tem garantido há anos o acesso de pessoas que não puderam, por algum motivo, realizar os estudos escolares na idade regular. Alinhado a esse processo desvela-se a dita função reparadora, que tem como foco garantir o acesso aos bancos escolares do público da EJA. Pois, nesse sentido,

\begin{abstract}
Avançar numa nova concepção de EJA significa reconhecer o direito a uma escolarização para todas as pessoas, independentemente de sua idade. Significa reconhecer que não se pode privar parte da população dos conteúdos e bens simbólicos acumulados historicamente e que são transmitidos pelos processos escolares. Significa reconhecer que a garantia do direito humano à educação passa pela elevação da escolaridade média de toda a população e pela eliminação do analfabetismo (HADDAD, 2007, p. 15).
\end{abstract}

Mesmo diante dos avanços que a modalidade EJA alcançou nos últimos anos, quando nos referimos ao acesso, permanência e êxito das pessoas idosas, ainda se percebem grandes lacunas. Pois desconhecemos ações, mesmo que pontuais, voltadas à adequação da modalidade ao público, sobretudo aos idosos. A escola para esses indivíduos tem um sentido que vai além da escolarização. Sobre isso, Barbosa (2016, p.37-38) diz que "assim, a aprendizagem é essencial para os idosos e as atividades desempenhadas nas escolas de EJA são fundamentais para garantir uma melhor qualidade de vida para os mesmos, pois quanto mais ativos forem, mais estarão inseridos na sociedade". Logo, podemos dizer que a escola é um espaço de socialização, de construção coletiva, de compartilhamento dos saberes de mundo, que possibilita a esses sujeitos uma nova forma de ser e viver nessa fase da vida. 
No entanto, é preciso ainda se ampliar o debate sobre o modelo de escola que temos hoje voltada para os idosos, pois a mesma está imbricada numa perspectiva conteudista, que visa muito mais a transmissão que o diálogo, ou mesmo pensar uma construção a partir da realidade dos alunos. Nesse sentido, a escola para esse grupo reforça em suma os silenciamentos, ratificando a reprodução dos distanciamentos. Por outro lado, é preciso pensar além dos desafios que a escola necessita superar para atender aos idosos, trata-se de pensar a escola na visão dos próprios indivíduos. Pois,

A presença dos velhos na escola, a possibilidade e complexidade de uma Pedagogia da velhice, são questões merecedoras de reflexões no contexto da educação pública atual. É uma atitude política porque convoca a sociedade a pensar uma agenda social e política para o idoso (PEREIRA, 2012, p.13).

Assim, a presença do idoso na escola emerge uma urgência em se pensar ações cunhadas para esse segmento etário que é crescente. Trata-se de uma forma de articular a partir da própria realidade do sujeito políticas públicas permanentes e não compensatórias que lhes propiciem uma vida adequada ao bem-estar, ao alcance dos seus objetivos e à educação ao longo da vida.

A autora levanta a necessidade de se debruçar sobre esse público e suas especificidades, assim como a escola pensa a Educação Infantil e os demais sujeitos que povoam esse importante espaço da construção do saber. A possibilidade de uma pedagogia da velhice é, na verdade, o surgimento e/ou a ampliação de um debate que já se aponta de forma iminente e necessária para um atendimento às necessidades de um grupo etário cada dia mais crescente em nosso país.

Trazer o idoso para a escola como um instrumento compensatório do tempo perdido não lhes garante realização. É preciso construir com essas pessoas um novo modelo de escola, cuja preocupação não esteja intrinsecamente ligada aos conteúdos programáticos exigidos pelo Estado. Pois,

A educação de jovens e adultos ocupou um lugar marginal na reforma da edu-
cação brasileira empreendida na segunda metade da década de noventa, pois os
condicionamentos do ajuste econômico levaram o governo a adotar uma estra-
tégia de focalização de recursos em favor da educação fundamental de crianças
e adolescentes. Não se pode atribuir isso à falta de um marco jurídico adequa-
do, pois as leis e normas vigentes - Constituição Federal, Lei de Diretrizes e
Bases da Educação Nacional, Lei do Plano Nacional de Educação, Diretrizes
Curriculares para a Educação de Jovens e Adultos - asseguram o direito público
subjetivo à educação, independentemente de idade, e concedem a necessária
flexibilidade para organizar o ensino de acordo com as necessidades de apren-
dizagem dos jovens e adultos. O problema não está nas leis, mas na política
educacional (DI PIERRO, 2005, p. 24).

Trata-se em suma da ausência de uma política de Estado que atenda, de fato, as necessidades dos sujeitos que buscam a EJA. No entanto, mesmo com um modelo de escola que, grosso modo, não atende as necessidades de jovens, adultos e principalmente idosos, é visível o crescimento das matrículas desse último grupo etário nos últimos anos. Diante 
desse fato, apresentamos e refletimos a seguir, à luz dessa perspectiva, tendo como pano de fundo a Educação de Jovens e Adultos no município de João Pessoa-PB, dados estatísticos referentes à presença dos idosos na EJA.

\section{Idosos na EJA no MunicíPio de João Pessoa-PB}

Inicialmente é preciso compreender como se organiza o atendimento na modalidade EJA pela Prefeitura Municipal de João Pessoa. Considerando as informações oficiais entre os anos de 2014 e 2018, analisaremos os dados numéricos referentes às matrículas gerais nessa modalidade e os recortes etários que definem as pessoas idosas (a partir dos 60 anos). Para esses sujeitos, a EJA representa muito mais que uma unidade escolar,

[...] representa uma dívida social não reparada para com os que não tiveram acesso à escola e nem domínio da escrita e leitura como bens sociais, na escola ou fora dela, e tenham sido a força de trabalho empregada na constituição de riquezas e na elevação de obras públicas (BRASIL, 2000, p.05).

Assim, a modalidade em voga ascende como um elemento fundante na transformação social de homens e mulheres, adultos e idosos, que não tiveram acesso e/ou tiveram a educação negada na idade regular. Diante desse cenário, a EJA no Brasil tem sido um dos grandes desafios no contexto atual, uma vez que as políticas públicas para essa modalidade não passaram de propostas pontuais, em sua maioria, que não a consolidaram na expectativa almejada, pois, em que pese,

A discussão das políticas públicas no contexto da Educação de Jovens e Adultos
compreende, preliminarmente, o reconhecimento dos direitos das pessoas jo-
vens e adultas a partir de uma visão que os considere como sujeitos que vivem,
historicamente, processos de exclusão, sendo privados dos direitos sociais, so-
bretudo, a educação e o lazer. Isso traduz o campo da EJA como um espaço
que precisa ser repensado na direção do comprometimento com a articulação
e instauração das políticas públicas para a EJA, pois se entende que os refle-
xos negativos dos jovens relacionados aos conflitos familiares, criminalidade,
dentre outros, na sociedade, é uma questão, sobretudo, política (GOMES; MO-
RAES, 2018, p.01).

A ausência de políticas públicas alinha-se com a desconstrução da EJA a partir do fechamento da oferta de matrículas em muitos municípios, país afora, a exemplo de João Pessoa. Isso tem chamado atenção em virtude do aumento da população idosa.

Não diferentemente dos demais municípios, João Pessoa tem reforçado a diminuição do número de turmas de EJA. No Quadro 1, podemos perceber que em uma década, o município retirou da sociedade 26 escolas que ofertavam a modalidade EJA. Sendo assim, quais seriam as motivações para o fechamento de tais unidades? Que elementos foram fundantes nesse processo de desaparecimento dessas salas? Quais prejuízos a sociedade sofrerá com tal ação? Muitos são os questionamentos levantados diante desse processo de esvaziamento das escolas de EJA. 
Quadro 1- Quantidade de escolas que ofertam EJA

na Prefeitura Municipal de João Pessoa-PB.

\begin{tabular}{|c|c|}
\hline Ano & Escolas com atendimento em EJA na PMJP \\
\hline $\mathbf{2 0 0 9}$ & 86 \\
\hline $\mathbf{2 0 1 0}$ & 81 \\
\hline $\mathbf{2 0 1 1}$ & 80 \\
\hline $\mathbf{2 0 1 2}$ & 81 \\
\hline $\mathbf{2 0 1 3}$ & 81 \\
\hline $\mathbf{2 0 1 4}$ & 81 \\
\hline $\mathbf{2 0 1 5}$ & 80 \\
\hline $\mathbf{2 0 1 6}$ & 79 \\
\hline $\mathbf{2 0 1 7}$ & 62 \\
\hline $\mathbf{2 0 1 8}$ & 60 \\
\hline
\end{tabular}

Fonte: MEC/INEP/DEED/ Subgerência de Estatística/SEECT/PB.

Os dados expostos nos convidam a refletir acerca das possíveis motivações que levaram ao fechamento de mais de duas dezenas de unidades educacionais ofertantes da EJA em um curto período de tempo, mas, por outro lado, nos chama atenção para uma possível organização polarizada dessas unidades. Enfim, trata-se de questões que merecem certo aprofundamento, pois adiante perceberemos que embora tenhamos a perda de um quantitativo de escolas considerável, as matrículas para essa modalidade não caíram na mesma proporção.

O fenômeno apresentado no quadro está diretamente ligado a dois importantes aspectos, quando nos voltamos para o campo interno da escola. O primeiro é o acesso, que está garantido em lei e depende exclusivamente da oferta. E o segundo no que tange à permanência, aspecto que está ligado aos processos desenvolvidos dentro da própria escola. Nesse movimento, um aspecto relevante é a relação que a escola constrói com seus sujeitos na modalidade EJA, pois não se trata apenas de transpor metodologias e estratégias do Ensino Regular, mas dialogar com os indivíduos para a construção da própria identidade da EJA e, assim, garantir a aprendizagem para essas pessoas.

Embora o fechamento de turmas de EJA seja um problema histórico e recorrente, ainda não se conseguiu avançar no tocante a minimizar tais efeitos, ou mesmo torná-los menos prejudiciais à oferta dessa modalidade. Tal ação tem ido de encontro aos documentos legais que garantem, em sua maioria, o "direito à educação", como preconizado no próprio Estatuto do Idoso. Nesse sentido, eleva-se,

\footnotetext{
A defesa pela escolarização plena para todos (incluindo as pessoas marginalizadas) se deve ao fato de que a escola continua socialmente relevante, lugar de aquisição dos conhecimentos acumulados pela humanidade, portanto, o acesso a ela significa, consequentemente, inserção social, lugar de sociabilidade e que expressa em si a educação formal [...] (PEREIRA, 2015, p.31961).
}

Trata-se, sobretudo, de valorizar e ampliar a oferta das salas de EJA, possibilitando, assim, $\mathrm{o}$ fortalecimento dessa modalidade. Nesse movimento, também se faz necessário 
ofertar uma melhor aprendizagem para os que buscam essa modalidade. A ausência de formação de professores para atuar na EJA tem se apresentado também como um grande desafio a ser superado, tendo como destaque as formações aligeiradas e que não dialogam com as necessidades da modalidade em questão. A presença de profissionais que estão em fim de carreira e/ou que não atendem ao perfil docente para a modalidade, amplia o debate sobre os problemas da EJA. Enfim, muitas são as questões que envolvem o fechamento de escolas e a diminuição da oferta.

Mesmo diante da diminuição de classes de EJA no município de João Pessoa-PB, os números oficiais mostram uma ascendência no número de matrículas, sobretudo, quando nos referimos aos idosos. Outro aspecto bastante importante face ao desmonte das escolas que ofertam a EJA tem sido as motivações pela redução de salas de aula para essa modalidade, como observa Ventura (2016, p. 25100-25101). Assim,

\begin{abstract}
Nos últimos anos, um fenômeno observado nesse campo é que o atendimento aos jovens e adultos, que sempre foi de pequena monta, vem regredindo ainda mais. A oferta, nesse formato inadequado e limitado, acaba por favorecer o esvaziamento das turmas. O mais grave é que esse declínio por parte dos alunos tem sido usado para explicar o fechamento de turmas e até mesmo para justificar o encerramento da oferta da modalidade em várias escolas. Em suma, os próprios alunos da EJA estão sendo responsabilizados pela diminuição de matrículas.
\end{abstract}

Trata-se de uma justificativa para o fechamento das salas de EJA, a diminuição da oferta sendo lançada como responsabilidade dos próprios sujeitos da modalidade que evadem ao longo do processo. No entanto, é preciso aprofundar-se nas motivações da evasão, que em muitos casos residem no fato da escola não atender in loco aos anseios dos sujeitos ali imersos. De uma forma geral, a escola atende as perspectivas apontadas pelo seu mantenedor, que é o Estado, deixando de lado as necessidades dos indivíduos nela inseridos.

Em meio ao debate acerca da diminuição da oferta de salas de aula de EJA, temos visualizado nos dados estatísticos oficiais a presença cada vez maior de pessoas idosas, uma vez que se trata de um movimento mundial o envelhecimento da população.

Para compreender esse importante cenário, apresentamos a seguir a série histórica das matrículas na EJA das escolas municipais de João Pessoa, nos últimos cincos anos, ou seja, entre os anos de 2014 e 2018, com ênfase para o recorte etário dos 40 aos 60 anos ou mais (adultos maduros e idosos), matriculados nos Ciclos I e II (Ciclos iniciais) e Ciclos III e IV (Ciclos finais) ambos do Ensino Fundamental.

É bem visível o distanciamento entre a manutenção das matrículas na EJA no município de João Pessoa e o fechamento das escolas ofertantes dessa modalidade como apresentado no Quadro 1. Essa relação não representa um diálogo coerente entre os índices estatísticos e a ação desenfreada de redução do número de escolas que ofertam a EJA no município em questão 
Quadro 2: O idoso na EJA no município de João Pessoa-PB

\begin{tabular}{|c|c|c|c|c|c|}
\hline $\begin{array}{c}\text { Série } \\
\text { Histórica }\end{array}$ & $\begin{array}{c}\text { Total de } \\
\text { Matrículas }\end{array}$ & $\begin{array}{c}\text { Alunos com } \\
\text { 60 ou mais } \\
\text { matriculados } \\
\text { nos } \\
\text { Ciclos Iniciais }\end{array}$ & $\begin{array}{c}\text { Alunos com } \\
\text { 60 ou mais } \\
\text { matriculados } \\
\text { nos } \\
\text { Ciclos Finais }\end{array}$ & $\begin{array}{c}\text { Total de } \\
\text { idosos } \\
\text { matriculados }\end{array}$ & $\begin{array}{c}\text { Porcentagem } \\
\text { de Idosos na } \\
\text { EJA nas escolas } \\
\text { municipais de } \\
\text { João Pessoa-PB }\end{array}$ \\
\hline $\mathbf{2 0 1 8}$ & 8.317 & 281 & 106 & 387 & $4,66 \%$ \\
\hline $\mathbf{2 0 1 7}$ & 8.934 & 329 & 117 & 446 & $4,99 \%$ \\
\hline $\mathbf{2 0 1 6}$ & 10.078 & 361 & 93 & 454 & $4,50 \%$ \\
\hline $\mathbf{2 0 1 5}$ & 9.914 & 371 & 90 & 461 & $4,65 \%$ \\
\hline $\mathbf{2 0 1 4}$ & 11.985 & 394 & 83 & 477 & $3,98 \%$ \\
\hline
\end{tabular}

Fonte: MEC/INEP/DEED/Sub gerência de Estatística/SEETEC/PB.

De acordo com os números apresentados no Quadro 2, percebemos que o público idoso vem se mantendo em uma média de porcentagem que nos chama atenção, pois trata-se de um grupo que busca a escola por diferentes expectativas para além da qualificação para o mercado de trabalho. Sobre esse cenário, percebe-se que,

\footnotetext{
A cada dia, aumenta a população da Educação de Jovens e Adultos (EJA) pela presença daqueles que não puderam frequentar em idade regular (escola negada) ou porque fracassaram no ensino regular, por sucessivas repetências e evasões (escola abandonada) (PEREIRA, 2012, p.12).
}

Segundo o exposto, dois importantes aspectos são evidenciados no sentido da presença na EJA. O primeiro, pela escola negada, quando por diferentes motivos o acesso é negado na idade escolar, e o segundo, que trata do abandono da escola, incluindo-se o insucesso escolar. São dois importantes aspectos para nos conduzir a uma reflexão sobre o retorno à escola, sobretudo, o retorno dos idosos, que viveram a idade escolar em um diferente momento histórico, social, político e econômico de nosso país, em que as dificuldades eram bem mais acentuadas.

O retorno dos idosos à escola, no município de João Pessoa, tem se mantido numa porcentagem média, girando na casa dos $4 \%$ do total das matrículas nos últimos 4 anos. Essa presença tem nos inquietado, pois se trata de um público específico, cujas orientações no Estatuto do Idoso requerem da escola algumas adaptações, desde o currículo até a própria metodologia. Tais mudanças são fundantes para a manutenção desse público no contexto da sala de aula. A presença dos idosos na escola empreende um esforço que vai além do espaço da sala de aula. Trata-se de pensar esses sujeitos numa perspectiva bem mais ampla. Sobre isso, Pereira (2012, p. 13) assevera que:

A presença dos velhos na escola, a possibilidade e complexidade de uma Pedagogia da velhice, são questões merecedoras de reflexões no contexto da educação pública atual. É uma atitude política porque convoca a sociedade a pensar uma agenda social e política para o idoso. 
Alinhando o exposto aos dados das matrículas de idosos na EJA em João Pessoa, destaca-se a necessidade da ampliação desse debate para que seja possível a criação de mecanismos que valorizem cada vez mais a presença desses indivíduos no contexto escolar. Essa presença é reforçada por inúmeros aspectos, entre os quais,

\footnotetext{
É possível afirmar que a educação pode auxiliar os idosos a perceber a necessidade de mudança, de união, a sentir a força que têm, valorizando-se, recuperando sua autoestima e, assim, efetiva e plenamente exercer sua cidadania, lutar por seu reconhecimento, por seus direitos, beneficiando a criação de espaços em que possam tornar visíveis suas necessidades (ALMEIDA; 2017, p.03).
}

Em meio a diferentes perspectivas, a busca pela escola nessa fase da vida tem relação com a ruptura de um conceito atribuído às pessoas idosas que não se sustenta mais no contexto atual. Pois, para boa parte da população, o idoso é um ser inoperante, que ao aposentar-se deve ficar em casa, ou mesmo fazer atividades manuais para que o tempo passe. $\mathrm{O}$ ingresso na escola desconstrói toda essa concepção preconceituosa que envolve o ser idoso. Ainda que de forma discreta, a manutenção do percentual de idosos apresentada no Quadro 2 aponta para o fato de que esse grupo etário deve manter-se nesse espaço, e isso está diretamente ligado às questões de envelhecimento da população, pois existe uma ascendência desse grupo conforme abordamos no início do texto.

Ainda refletindo sobre os dados expostos, percebe-se que o quantitativo de idosos matriculados na EJA no município de João Pessoa é bastante considerável nos Ciclos Iniciais (I e II) do Ensino Fundamental, aspecto que aponta para a perspectiva da alfabetização, visto que é nessa fase que se dá o processo de aquisição da leitura e escrita. Sobre esse processo, Silva e Taam $(2009$, p.05) afirmam que a "prática docente junto aos idosos nos tem revelado que a grande preocupação destes sujeitos que voltam a estudar é aprender a ler e escrever", reforçando, portanto, o ingresso desses sujeitos nessa modalidade.

Assim, esses números já sinalizam uma ruptura entre o ingresso nos primeiros ciclos e a transposição serial para os ciclos finais. Pois, ao analisar tais dados não percebemos esse avanço. Desse modo, dois movimentos relevantes estão embutidos nos dados: o primeiro acerca da evasão, uma vez que os números não evoluem para os ciclos finais; o segundo seria a negação à seriação através de artifícios como a desistência em determinado tempo do ano letivo, garantindo assim, o retorno no ano seguinte para o mesmo ciclo. Contudo, de acordo com os dados, percebe-se que existe um discreto crescimento entre os anos de 2014 e 2018 de idosos nos ciclos finais.

Os dados apresentados revelam que, assim como a própria sociedade que envelhece, a escola, em especial a modalidade EJA, tem sido o espaço de inserção desses indivíduos no campo educacional.

\section{Palavras finais}

Ao finalizar as reflexões tecidas ao longo deste estudo, percebe-se que, embora a EJA seja uma modalidade desafiadora em todos os seus aspectos, ela ainda é um espaço de construção do saber formal e da ampliação das relações sociais. Considerando a multiplicidade 
dos sujeitos atendidos na modalidade, faz-se necessário entender as especificidades dos grupos etários, no caso deste estudo, os idosos.

Os dados da série histórica obtidos e analisados demonstra claramente a ascendência na presença dos idosos nas escolas que ofertam a modalidade EJA no município de João Pessoa, reforçando, assim, a necessidade de pensar e articular na proposta local, elementos que corrobore para o acesso, a permanência e a conclusão dos estudos por parte deste grupo etário, considerando e atendendo, entre outros marcos legais, ao Estatuto do Idoso, que preconiza a flexibilização das metodologias para atendimento a esse público.

Pois, embora tenhamos grupos de diferentes idades cronológicas, todos comungam do mesmo direito constitucional, o direito à educação. Garantir a educação não é ofertar inúmeras vagas, mas possibilitar a esses indivíduos uma aprendizagem que traga sentido para sua vida.

Nesse contexto de povoamento da EJA, os idosos nos chamam atenção. Essa preocupação é refletida pelo envelhecimento populacional que ascende em uma ligeira proporção. Dessa forma, os dados revelados de matrículas na EJA no município de João Pessoa direcionam o nosso olhar para a escola e para esse público. A EJA deve urgentemente compreender esse processo para assim melhor atender esse grupo tão específico.

Os dados estatísticos apresentados vislumbram uma linha tênue da presença de pessoas idosas na EJA no município de João Pessoa entre 2014 e 2018, aspecto que amplia o debate sobre o modelo de escola que necessitamos para atender a esse público, haja vista a garantia do direito constitucional de acesso à escola. Os percentuais analisados ascendem a uma preocupação mundial, o envelhecimento populacional. Pois, trata-se de um grupo de indivíduos que apresentam inúmeras especificidades.

Diferentemente dos demais grupos, os idosos trazem uma carga de necessidades singulares e que não são as mesmas variáveis dos demais ali existentes. Nesse contexto, o envelhecimento deve ser encarado como um problema de cunho social, e que faz parte das perspectivas de todos os indivíduos.

No que tange ao processo de escolarização de idosos, como vimos nos dados referentes às matrículas da EJA no município de João Pessoa, alguns aspectos devem ser considerados para que se possa atender tal demanda de modo a garantir a permanência e a conclusão:

- Conhecer seus sujeitos, suas origens e vivências garante uma melhor intervenção;

- Possibilitar aspectos que integrem os diferentes grupos etários presentes na EJA;

- Realizar a promoção de formação de professores que atenda também a demanda em questão;

- Conhecer e debater questões relativas ao envelhecimento populacional, entre outros.

Essas são apenas algumas das provocações necessárias à EJA no município de João Pessoa, de modo a promover a manutenção da ascendência das matrículas desse grupo etário. Repensar o lugar da escola na vida dos idosos e de outros sujeitos garante a promoção de uma educação que integre, que liberte e que promova uma aprendizagem de sentido para a vida dos mesmos.

Valorizar a presença crescente desse público na EJA também permite o enriquecimento cultural e a ruptura da relação preconceituosa que existe entre esse grupo e os demais substratos sociais, como os jovens, por exemplo. 
Assim, as reflexões aqui pontuadas, contribuem para que possamos ampliar inicialmente o debate acerca do movimento escola e idoso no município de João Pessoa-PB e mais especificamente que possamos pensar e articular políticas públicas no campo da educação que proporcione a pessoa idosa uma melhor condição de vida e bem-estar social e possiblidade de acesso e permanência no espaço de sala de aula da escola pública.

\section{REFERÊNCIAS}

ALMEIDA, C. M. R. Educação de Jovens e Adultos: a escola como espaço de inserção social e sua contribuição para o processo de socialização e consolidação da autonomia de alunos idosos. 2017. 122p. Trabalho Final de Curso (Pedagogia). Faculdade de Educação da Universidade de Brasília - FE/UnB. Brasília, 2017.

BARBOSA, G. R. P. A importância da educação na velhice: alunos idosos na EJA. Escritos e Escritas na EJA. Porto Alegre, n. 5, 2016. p. 30-39.

BRASIL. [Constituição (1988)]. Constituição da República Federativa do Brasil. Brasília, Senado Federal, Coordenação de Edições Técnicas, [2016]. Disponível em: <https:// www2.senado.leg.br/bdsf/bitstream/handle/id/518231/CF88_Livro_EC91_2016.pdf $>$. Acesso em: 03 dez. 2019.

BRASIL. Lei no 9.394, de 20 de dezembro de 1996. LDB: Lei de diretrizes e bases da educação nacional. 2 ed. Brasília: Senado Federal, Coordenação de Edições Técnicas, [2018]. Disponível em: < https://www2.senado.leg.br/bdsf/bitstream/handle/id/544283/lei_de_diretrizes_e_bases_2ed.pdf $>$. Acesso em: 03 dez. 2019.

BRASIL. Lei $\mathbf{n}^{\circ} \mathbf{1 0 . 7 4 1}$, de $1^{\circ}$ de outubro de 2003. Estatuto do Idoso. Brasília: Presidência da República, [2003]. Disponível em: <http://www.ceeja.ufscar.br/marco-acao-belem>. Acesso em: 03 dez. 2019.

BRASIL. Ministério da Educação. Conselho Nacional de Educação. Parecer n 11/2000. Trata das Diretrizes Curriculares Nacionais para Educação de Jovens e Adultos. Brasília: Câmara de Educação Básica, [2000]. Disponível em: <http://portal.mec.gov.br/cne/arquivos/pdf/pceb011_00.pdf >. Acesso em: 03 dez. 2019.

BRASIL, Ministério da Educação. Sub Gerência de Estatística. Secretaria de Educação, Cultura e Tecnologia do Estado da Paraíba. João Pessoa: 2020.

DI PIERRO, M. C. Um balanço da evolução recente da educação de jovens e adultos no Brasil. Construção coletiva: contribuições à educação de jovens e adultos. Brasília: UNESCO, MEC, RAAAB, 2005. p. 17-30. Disponível em: <http://portal.mec.gov.br/index.php?option $=$ com_docman\&view $=$ download $\&$ alias $=655$-vol3 const-pdf\&category slug=documentos-pdf\&Itemid=30192>. Acesso em: 20 mar. 2020. 
GOMES, N. R. C.; MORAES, L. C. S. Desafios das políticas públicas atuais para a educação brasileira de jovens e adultos. In: V CONEDU, 2018, Olinda-PE. Anais..., Olinda: Realize Editora, 2018. Disponível em: <http://www.editorarealize.com.br/revistas/conedu/ trabalhos/TRABALHO_EV117_MD1_SA12_ID112_07092018154743.pdf >. Acesso em: 18 mar. 2020.

HADDAD, S. Por uma nova cultura de Educação de Jovens e Adultos, um balanço de experiências de poder local. Novos caminhos em Educação de Jovens e Adultos - EJA. São Paulo: Global, 2007. Disponível em: <http://www.anped.org.br/sites/default/files/trabalho_encomendado_gt18_-_sergio_haddad_-_int.pdf>. Acesso em: 21 mar. 2020.

MENDES, M. R. S. S. B. et al. A situação social do idoso no Brasil: uma breve consideração. Acta Paulista de Enfermagem, São Paulo, v. 18, n. 4, 2005. p. 422-6.

ORGANIZAÇÃO DAS NAÇÕES UNIDAS PARA A EDUCAÇÃO, A CIÊNCIA E A CULTURA. Sexta conferência internacional de educação de adultos, 2010, Brasília. Marco de Ação de Belém, Brasília: MEC,2010.

PEREIRA, J. M. M. A escola do riso e do esquecimento: idosos na educação de jovens e adultos. Educação em Foco, Juiz de Fora, v. 16, n. 2, 2012. p. 11-38.

PEREIRA, A. Os novos sujeitos da EJA e da educação social: as pessoas em situação de vulnerabilidade social. In: XII Congresso Nacional de Educação - EDUCERE, 2015, Curitiba. Anais..., Curitiba: FACED, 2015. <Disponível em: https://educere.bruc.com.br/ arquivo/pdf2015/21013_8371.pdf>. Acesso em: 20 mar. 2020.

SCHNEIDER, R. H.; IRIGARAY, T. Q. O envelhecimento na atualidade: aspectos cronológicos, biológicos, psicológicos e sociais. Estudos de Psicologia. Campinas, v. 25, n. 4, 2008. p. 585-593.

SILVA, M. C. B.;TAAM, R. O idoso e os desafios à sua educação escolar. In: Seminário de Pesquisa do PPE, 2009, Maringá-PR. Anais..., Maringá: UEM, 2009. Disponível em: <http://www.ppe.uem.br/publicacoes/seminario_ppe_2009_2010/pdf/2009/51.pdf >. Acesso em: 21 Mar. 2020.

UNESCO. Confintea VI. Marco de Ação de Belém. Brasília: UNESCO, MEC, 2010.

VENTURA, J. A oferta de Educação de Jovens e Adultos de nível médio no estado do Rio de Janeiro: primeiras aproximações. Revista Brasileira de Educação de Jovens e Adultos, v. 04, n.8, 2016. p. 09-35. Disponível em: <https://educere.bruc.com.br/arquivo/ pdf2017/27273_13815.pdf >. Acesso em: 20 mar. 2020. 
VENTURA. J. P. A redução da oferta de educação de jovens e adultos de nível médio no estado do rio de janeiro. In: XI Congresso Nacional de Educação - EDUCERE, 2013, Curitiba. Anais..., Curitiba: PUCPR, 2013. Disponível em: <https://educere.bruc.com.br/ arquivo/pdf2017/27273_13815.pdf $>$. Acesso em: 20 Mar. 2020.

WORLD HEALTH ORGANIZATION. Envelhecimento ativo: uma política de saúde / World Health Organization. Tradução Suzana Gontijo. Brasília: Organização Pan-Americana da Saúde, 2005.

\section{DADOS DOS AUTORES}

\section{Saulo José Veloso de ANdrade}

Doutorando em Educação pelo Programa de Pós-Graduação em Educação - PPGE/UFPB. Mestre em Formação de Professores - UEPB, Licenciado em Pedagogia pela UFPB. saulojosesjva@gmail.com

\section{THEÓFFILLO SILVA LOPES}

Doutorando em Educação pelo Programa de Pós-Graduação em Educação - PPGE/UFPB. Mestre em Desenvolvimento e Meio Ambiente pela Universidade Federal da Paraíba UFPB. Graduado em Pedagogia pela Universidade Federal da Paraíba - UFPB. theoffillo@ outlook.com

\section{Eduardo Jorge Lopes da SiLVA}

Professor permanente do Programa de Pós-Graduação em Educação (PPGE/UFPB), linha de pesquisa Processo de Ensino-Aprendizagem. eduardojorgels@gmail.com

Submetido em: 03-07-2020

Aceito em: 31-03-2021 